\title{
Modeling and Simulation of a Novel Module for Thermoelectric Power Generation from Solar Photovoltaic Panels
}

\author{
Muhammad Suleman Malik ${ }^{1}$, Muhammad Naeem Arbab ${ }^{2}$, Bilal Mehmood ${ }^{3}$, Haseeb Aman $^{4}$, Hayat ${ }^{5}$, Pir Jalal ${ }^{6}$ \\ 1,2,3,4,5,6 University of Engineering \& Technology Peshawar (Pakistan). \\ suleman2113@gmail.com ${ }^{1}$, mnarbab@yahoo.com², bilal1208@gmail.com³, Haseebamaankhattak@gmail.com ${ }^{4}$, \\ hayat_ullah@hotmail.com ${ }^{5}$, pirjalal11@gmail.com ${ }^{6}$ \\ Received: 12 June, Revised: 19 June, Accepted: 21 June
}

\begin{abstract}
Electricity is a basic need of humans in this modern era and plays a role of a backbone in our daily life as well as in the economic growth of a country. The efficiency of a power system is very important parameter which helps in analyzing its overall performance. So due to this reason effective and efficient utilization of solar energy is very important. Heat losses occurs in solar panels which reduces power output and hence overall efficiency is decreased. These heat losses can be utilized in such a way that works as waste heat recovery system. This system uses light and heat energy of the sun. When sunlight strikes the PN Junctions of solar PV panels, photovoltaic electricity is produced. Whereas, heat of sun and heat losses in the solar panels can be utilized and temperature difference is created by different means so as to generate electricity using thermoelectric cells (TEC) which works on the principle of Seebeck effect. Electricity generated from both sources can be common pooled and feed to the load either directly or it can be stored in batteries. This makes the system more effective and efficient.
\end{abstract}

Keywords - Electricity, power generation, Seebeck effect, solar energy, solar panels.

\section{INTRODUCTION}

Electricity plays a major role in building the economy of a country. All the domestic, industrial, commercial and metropolitan areas need electricity for their daily operations. If the prices of electricity are low and it is available whole day without any interruption, then the products made by the industries or factories are large in quantity and cheap in price.

Pakistan is an under developed country, its economy is unstable and its energy sector is at continuous downfall. The resources available for electrical power generation are either not used properly or there is lack of facilities or there is absence of expertise to utilize it in an efficient and effective manner to generate electricity from it. Transmission losses in the existing outdated system, uncontrolled power theft, reduction of water available for hydroelectric power due to seasonal variations, increase in the prices of fuel has increased the difficulty in the system. There is a dip between the electricity generation and the demand so due to this reason we are facing electricity shortage. The electricity production in Pakistan from 2008 to 2018 is shown in Fig 1.

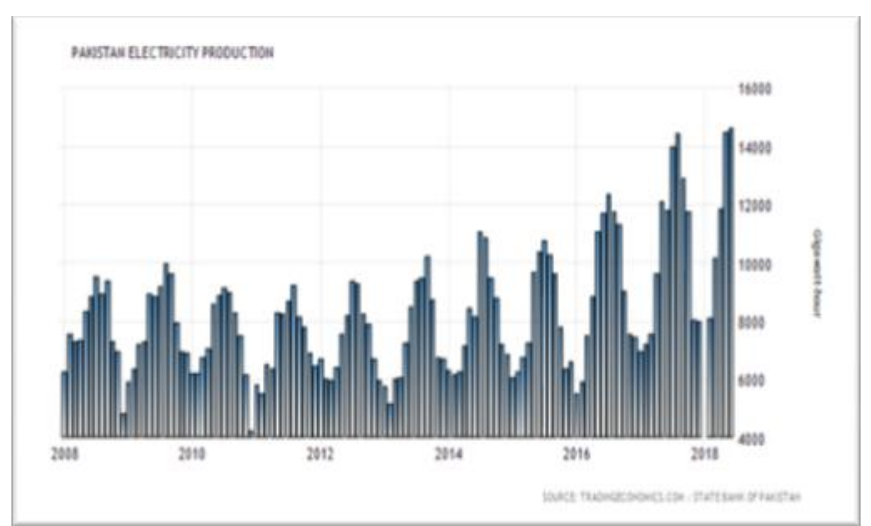

Figure 1. Electricity Generated during last 10 years in Pakistan [1]

During last five years, work has been done in the energy sector of Pakistan. From 2013 to 2018, 39 power projects were installed which added a capacity of $12,230 \mathrm{MW}$ to the national grid [2]. The energy of the sun is due to continuously occurrence of nuclear fusion reactions. When hydrogen atoms specifically protium or deuterium or hydrogen and helium are forced to combine by some external agents (energy) it releases a tremendous amount of energy in a form of light, heat and sound along with hydrogen or helium as a byproduct. Individually, fusion produces less energy as compared to fission but due to the presence of abundant amount of hydrogen on the surface of sun. The overall energy produced due to fusion is more in the sun if compared with the fission reaction.

Ongrid system is directly connected to the regional or national grid to supply electricity generated by different sources locally through bi-directional meters. ON grid system doesn't possess battery backup system. When grid supply is properly working and is switched on, ON grid system will work but when the feeders in grid station are switched off, ON grid system willn't supply electricity to the national grid [3].

Off grid system generates electricity and supply it to its local load along with storage facility without connecting it to regional or national grid is called OFF grid system. OFF grid system is connected with the battery backup. It can be 
connected with renewable as well as non-renewable sources such as wind turbines, hydro-turbines and diesel generators etc. It can be used to generate as well as store electricity in case of emergency or in case of cloudy weather or at night [4].

Hybrid system, which has both features of ON Grid and battery backup is called hybrid system. This system is not only connected to the regional or national grid but also charges the battery at the same time. Electricity is fed to the grid through bi-directional meters [5].

There are different methods of generating electricity including electricity generation from fossil fuels [6], Solar thermal power generation using heliostates to through light on a receiver tank [7] or using Seebeck effect for electrical power generation [8].

Solar radiations consist of infrared, visible light and ultraviolet rays as shown in Fig 2.

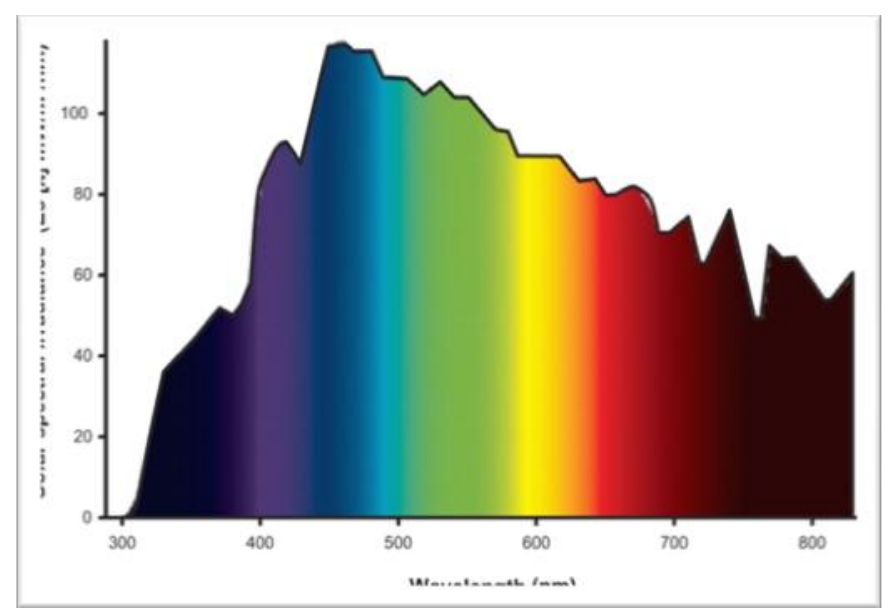

Figure 2. Spectral distribution of sun light [9]

\section{MATERIALS}

Thermoelectric cells are made up of semiconductor materials. These extrinsic semi-conductor materials consist of P-Type and N-Type Pallets. P-Type materials are made by doping group 3 elements of periodic table with silicon or arsenic and in doing so there is a deficiency of electrons i.e. a presence of hole so it is called P-Type semiconductor. Majority charge carriers are holes and minority charge carriers are electrons. Similarly, N-Type semiconductors are made by doping group 5 elements of periodic table with silicon or germanium and in doing so there is an excess of electron i.e presence of one extra electron so it is called N-Type semiconductor. Majority charge carriers are electrons and minority charge carriers [10-12]. The best thermoelectric materials for thermoelectric cells along with there figure of merit is shown in Fig 3.

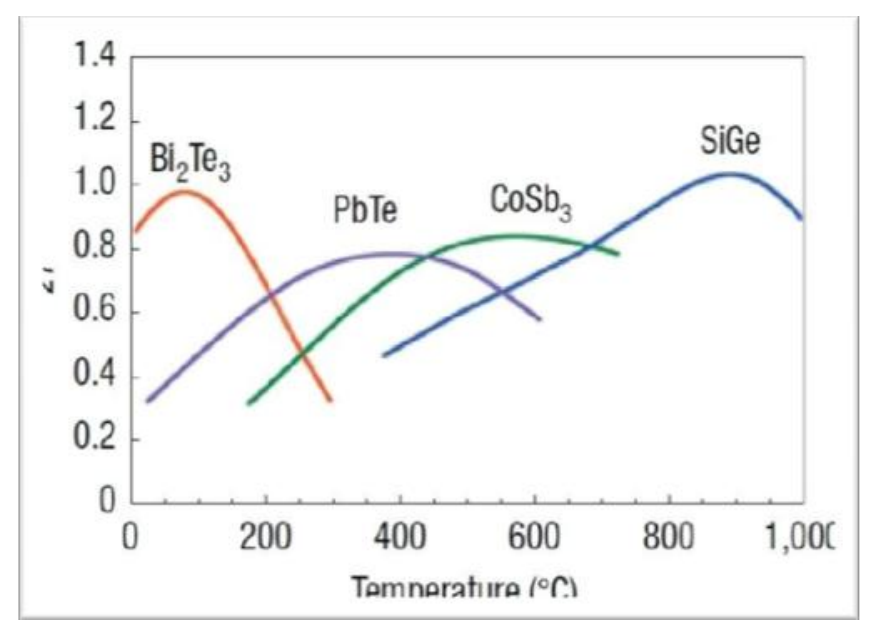

Figure 3. Figure of merit of different termoeletric materials at different temperatures [13].

Thermoelectric cells vary in size, depending upon power requirement [14]. The length and width of the cell is in range of 2.5 to $50 \mathrm{~mm}$ each and thickness is in range of 2.5 to $5 \mathrm{~mm}$ as shown in Fig 4.

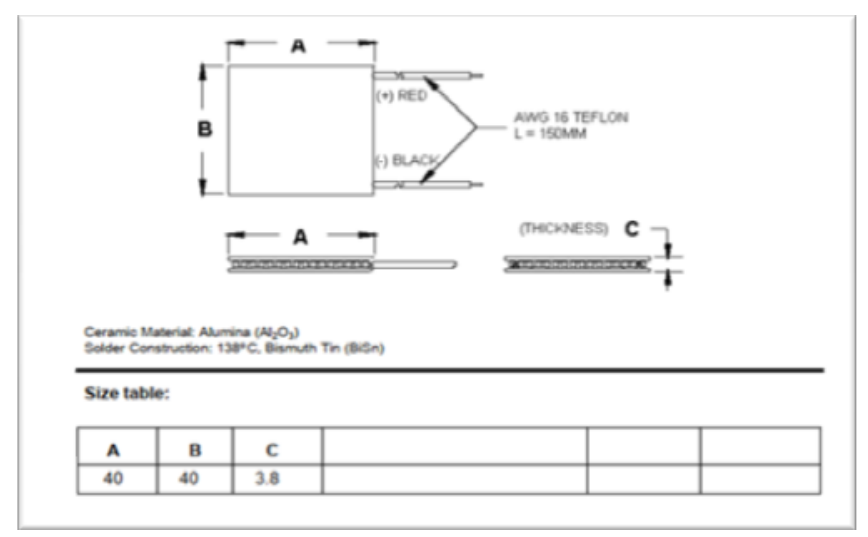

Figure 4. Dimensions of thermoelectric cell

When two thermoelectric cells are staked together with slight modifications in internal structure it is called two stage thermoelectric cell [15]. The efficiency of two stage thermoelectric cells is more than one stage thermoelectric cell [16]. Two stage thermoelectric cell is shown in Fig 5.

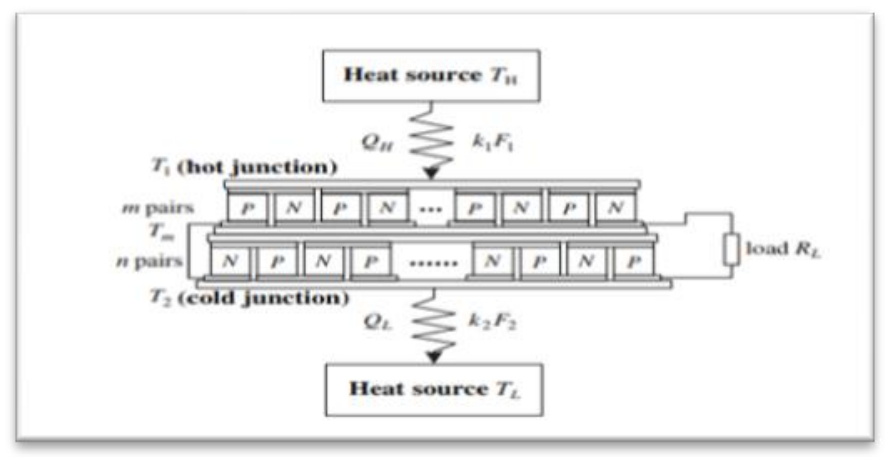

Figure 5. Two stage thermoelectric cell 


\section{Methodology}

Thermoelectric cells and solar panels are modeled in Simulink and Autocad. Thermoelectric cells can be attached on the backside of solar panels. The dimensions of solar panels areshown in Fig 6.

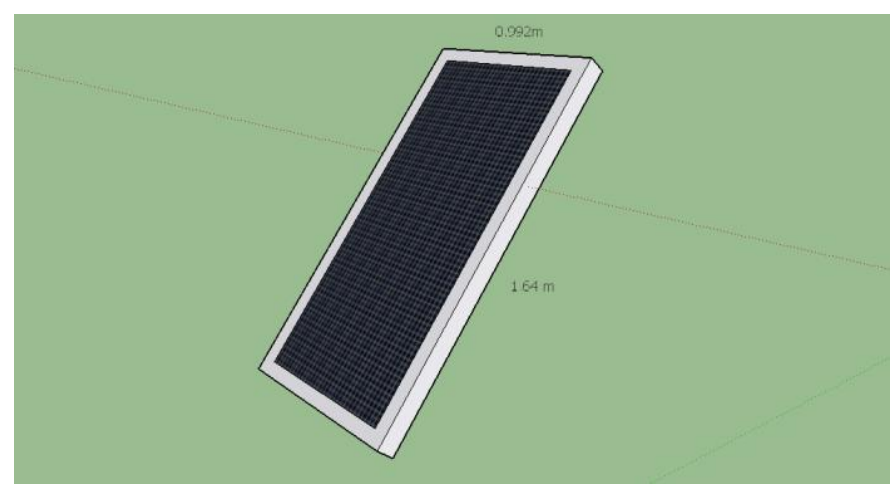

Figure 6. Dimensions of solar panel

Electrical power generated from thermoelectric cells mainly depends on Seebeck coefficient (S), Electrical resistance (R) and thermal conductance (K). So each parameter must be modeled separately in simulink.

Seebeck coefficient determines the voltage generated by thermoelectric cell. Simulink model of Seebeck coefficient of thermeoelectric cell is shown in Fig 7.

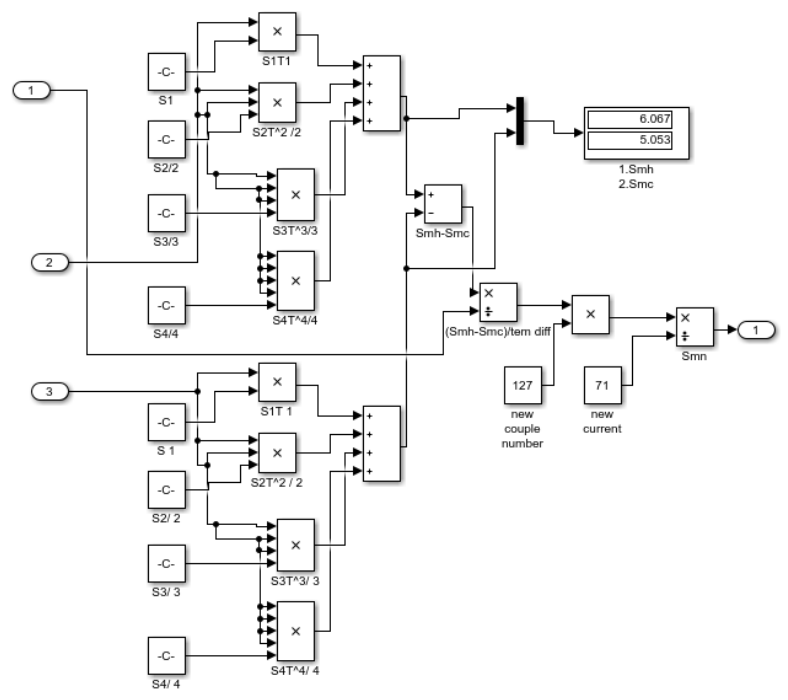

Figure 7. Simulink Model of Seebeck Coefficient

It determines the opposition faced by thermoelectric cell to the flow of electricity.Simulink model of electrical resistance of thermoelectric cell is shown in Fig 8.

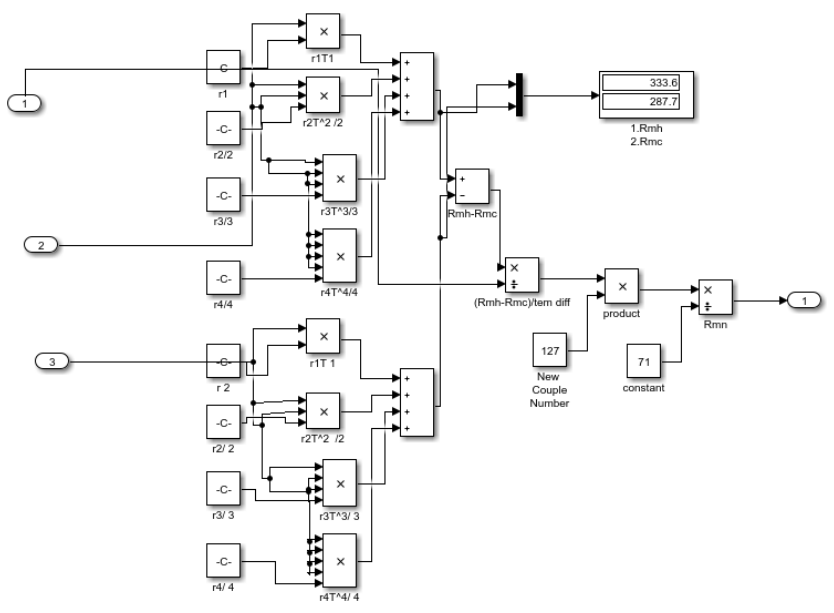

Figure 8. Simulink Model of Electrical Resistance

Thermal conductance determines the flow of heat with in a thermoelectric cell. Simulink model of thermal conductance of a thermoelectric cell is shown in Fig 9.

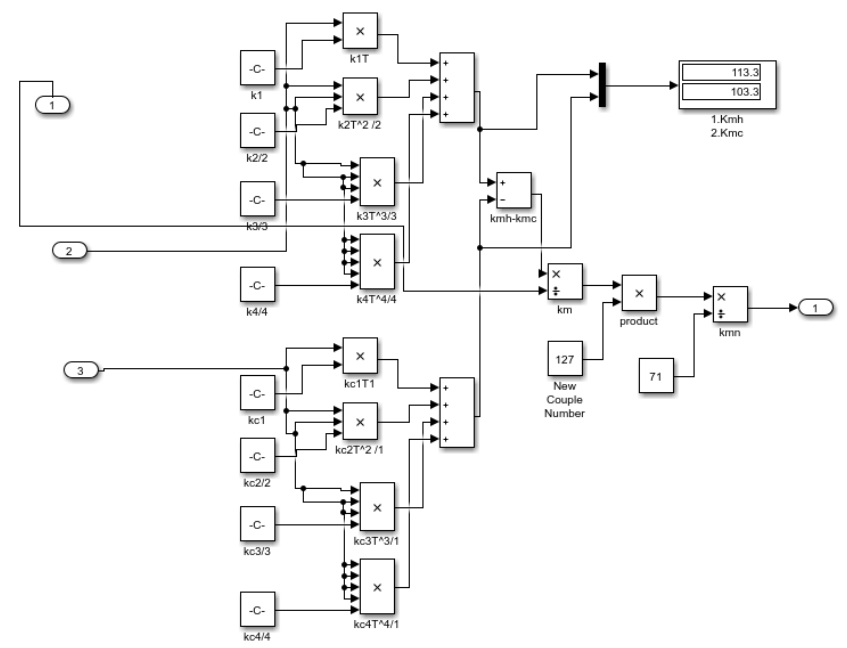

Figure 9. Simulink Model of Thermal conductance

The modeling of all the parameters of a commercially available thermoelectric cell is shown in Fig 10.

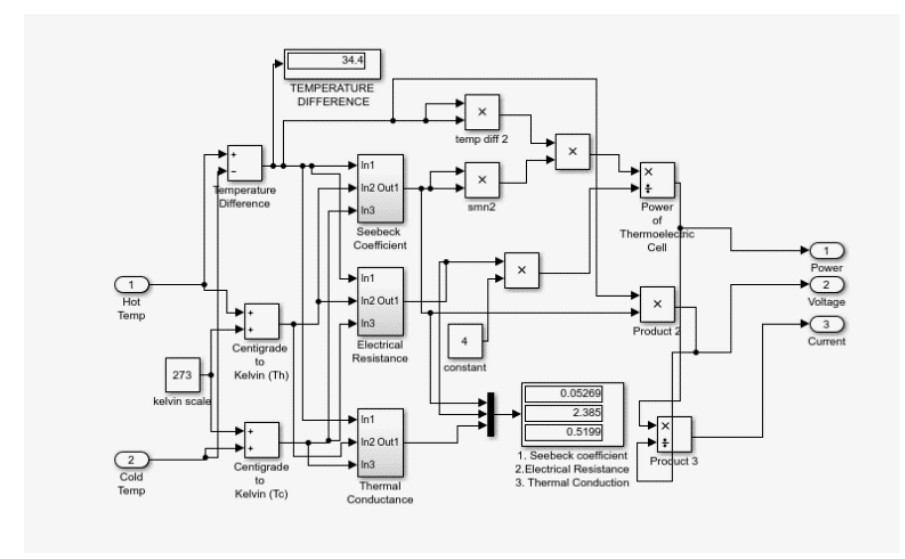

Figure 10. Simulink Model of commercially available thermoeletric cell 


\section{SimUlATIONS AND RESUlTS}

All the parameters of thermoelectric cells are simulated in Simulink. The variation of the parameters of thermoelectric cell with the rise in the temperature difference is shown in Fig 11. It is clear that with the rise in temperature difference the value of Seebeck coefficient changes slightly, value of resistance increases linearly, value of thermal conductance also changes slighty whereas the value of power changes slightly in the start but rises ecponentially with the increase in temperature.

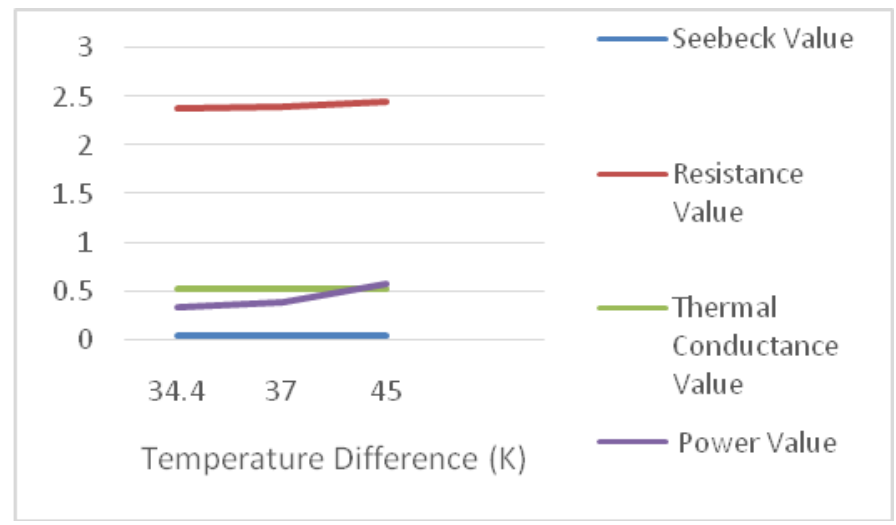

Figure 11. Variation of the parameters of thermoelectric cell with the rise in temperature.

If we integrate power of twenty solar panels with the power generated by thermieletric cell then the contribution of each sourves is shown in the form of a table 1 .

TABLE I. POWER GENERATION BY EACH SOURCE

\begin{tabular}{|c|c|c|c|c|}
\hline S.NO & $\Delta T(\mathrm{C})$ & $\mathbf{E}_{\text {Solar per year }}$ & $\mathbf{E}_{\text {Tec per year }}$ & $\mathbf{E}_{\text {Total per year }}$ \\
\hline 1 & 34.4 & \multirow{3}{*}{9581.25} & 12636.3 & 22217.55 \\
\cline { 5 - 5 } \cline { 4 - 5 } \cline { 4 - 5 } & 37 & & 14490.5 & 24071.75 \\
\hline 3 & 45 & & 21341.55 & 30922.8 \\
\hline
\end{tabular}

The share of electrical power by each source is shown in Fig 12. It is clear that power generation from thermoeletric system is more than that of solar panels system.

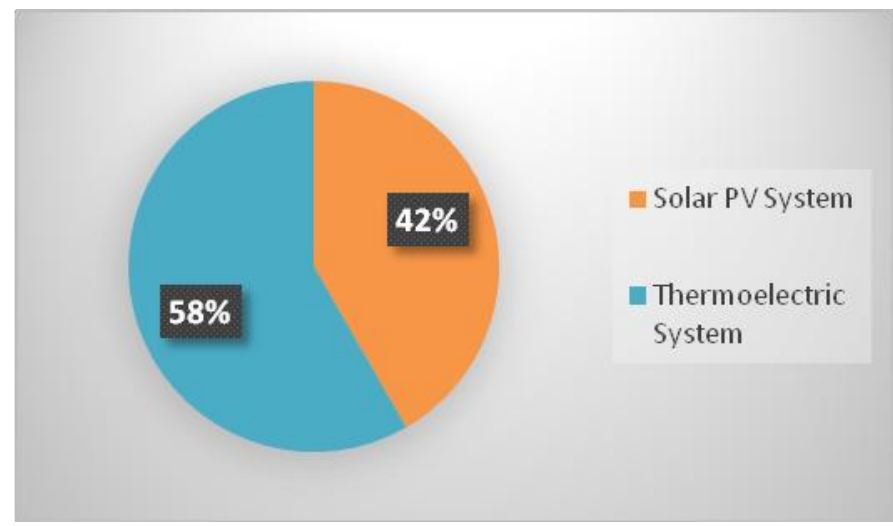

Figure 12. Share of eletrical power by solar PV system and Thermoelectric system.

\section{CONFLICT OF INTEREST}

The authors declare no conflict of interest.

\section{CONCUSLION}

It is concluded that with the increase in the temperature of solar panels, electrical power is reduced. So utilizing this temperature for electrical power generation by means of thermoelectric cells, we can increase the overall electrical power, by integrating both solar panels and thermoelectric cells. The overall output power is increased by adopting this method of integration of solar panels with thermoeletric cells.

\section{REFERENCES}

[1] Trading Economics, "Pakistan Electricity Production," Trading Economics, 2018 [Online] Available: https://tradingeconomics.com/pakistan/electricity-production.

[2] Ministry of Finance, "Pakistan Economic Survey 2017-2018," Ministry of Finance, Islamabad, 2017-2018.

[3] N. M. Kumar, M. S. P. Subathra and J. E. Moses, "On-Grid Solar Photovoltaic System: Components,Design Considerations, and Case Study," in $4^{\text {th }}$ International Conference on Electrical Energy Systems (ICEES), 2018.

[4] M. P. Monfort, S. L. Oña, D. Ribó-Pérez and S. Z. Djokic, "Modelling and Evaluating Performance of Large Off-Grid PV Systems for Water Pumping," in 2018 IEEE PES Innovative Smart Grid Technologies Conference Europe (ISGTEurope), Sarajevo, Bosnia-Herzegovina, 2018 .

[5] K. Alluhaybi, X. Chen and I. Batarseh, "A Grid Connected Photovoltaic Microinverter with Integrated Battery," in IECON 2018 - 44th Annual Conference of the IEEE Industrial Electronics Society, Washington, DC, USA, 2018

[6] D. A. Tillman, Coal-Fired Electricity and Emissions Control: Efficiency and Effectiveness, Butterworth-Heinemann, Elsevier, 2018.

[7] U. Pelay, L. Luo, Y. Fan, D. Stitou and MarkRood, "Thermal energy storage systems for concentrated solar power plants," Renewable and Sustainable Energy Reviews, vol. 79, pp. 82-100, 2017.

[8] S. Huang and X. Xu, "A regenerative concept for thermoelectric power generation," Applied Energy, vol. 185, pp. 119-125, 112017.

[9] M. Md. Kafiul Islam, "Performance assessment and degradation analysis of solar photovoltaic technologies: A review," Renewable and Sustainable Energy Reviews, vol. 78, pp. 554-587, 2017.

[10] M. Ibañez-Puy, J. Bermejo-Busto, C. Martín-Gómez, M. VidaurreArbizu and J. Sacristán-Fernández, "Thermoelectric cooling heating unit performance under real conditions", Applied Energy, vol. 200, pp. 303 314, 2017. Available: 10.1016/j.apenergy.2017.05.020

[11] D. Zhao and G. Tan, "A review of thermoelectric cooling: Materials, modeling and applications", Applied Thermal Engineering, vol. 66, no. 1-2, pp. 15-24, 2014. Available: 10.1016/j.applthermaleng.2014.01.074.

[12] H. Zhang, W. Kong, F. Dong, H. Xu, B. Chen and M. Ni, "Application of cascading thermoelectric generator and cooler for waste heat recovery from solid oxide fuel cells", Energy Conversion and Management, vol. 148, pp. 1382-1390, 2017. Available: 10.1016/j.enconman.2017.06.089.

[13] "Thermoelectrics", Thermoelectrics.matsci.northwestern.edu,2019. [Online].Available: http://thermoelectrics.matsci.northwestern.edu/thermoelectrics/index.ht ml. [Accessed: 20- Jun- 2019]

[14] D. Li, Y. Xuan, Q. Li and H. Hong, "Exergy and energy analysis of photovoltaic-thermoelectric hybrid systems", Energy, vol. 126, pp. 343 351, 2017. Available: 10.1016/j.energy.2017.03.042.

[15] H. Zhang, H. Xu, B. Chen, F. Dong and M. Ni, "Two-stage thermoelectric generators for waste heat recovery from solid oxide fue cells", Energy, vol. $\quad 132$, pp. 280-288, 2017. Available: 10.1016/j.energy.2017.05.005 
[16] K. Cheng, J. Qin, Y. Jiang, S. Zhang and W. Bao, "Performance comparison of single- and multi-stage onboard thermoelectric generators and stage number optimization at a large temperature difference", Applied Thermal Engineering, vol. 141, pp. 456-466, 2018. Available: 10.1016/j.applthermaleng.2018.05.127.

Muhammad Suleman Malik is a student of University of Engineering and Technology Peshawar.doing MS in Electrical engineering. He has written two research papers in international journals. His main research interest is electrical power generation.

Email: suleman2113@gmail.com

Muhammad Naeem Arbab is a professor at University of Engineering and Technology Peshawar. He got his Phd degree from University of Manchester, England. He has written 3 books in the field of electrical engineering o.e Electrical power generation, high voltage engineering and Control systems. He has published more than 25 research papers in local and international journals and conferences. Email: mnarbab@yahoo.com 